\title{
Acute and chronic effects of anteromedial globus pallidus stimulation in Parkinson's disease
}

\author{
Franck Durif, Jean-Jacques Lemaire, Bérengère Debilly, Gérard Dordain
}

\begin{abstract}
Objective-To evaluate the effects of acute and chronic stimulation in the anteromedial part of the globus pallidus internus (GPi) on the symptoms of patients with Parkinson's disease.

Methods-Six patients with severe Parkinson's disease (Hoehn and Yahr stage 4-5 in "off" drug condition) with motor fluctuations and levodopa induced dyskinesia (LID) were operated on. Chronic electrodes were implanted in the anteromedial GPi bilaterally in five patients and unilaterally in one patient. The effect of stimulation via the four contacts for each electrode $(n=11)$ was assessed postoperatively on the contralateral parkinsonian signs in the off condition and on the contralateral and ipsilateral LID in the "on" condition. The core assessement program for intracerebral transplantation protocol was performed before surgery and then 1, 3, and 6 months after surgery in on and off conditions and in on and off stimulation conditions.
\end{abstract}

Results-Stimulation performed postoperatively showed a significant improvement $(p<0.05)$ by $47 \%$ (contralateral rigidity) and $32 \%$ (contralateral bradykinesia) when stimulation was applied through the distal contact. Levodopa induced dyskinesias were improved by $95 \%$ (contralateral LID) and by $66 \%$ (ipsilateral LID) when stimulation was applied through the distal contact. Six months after the surgery, GPi stimulation in the off condition led to a mean improvement in the motor score of UPDRS by $36 \%$. The mean daily duration in the off state decreased by $52 \%(p<0.05)$. The mean duration of LIDs decreased by $68 \%$ $(p<0.05)$ and their severity by $53 \%$ $(\mathrm{p}<0.05)$.

Conclusion-Chronic stimulation in the anteromedial GPi shows that this is a safe and effective treatment for advanced Parkinson's disease with benefit sustained for at least 6 months.

(f Neurol Neurosurg Psychiatry 1999;67:315-321)

Keywords: Parkinson's disease, chronic stimulation, globus pallidus

Durif, Federation de

Montpied, BP 69,63003

Clermont-Ferrand, Cedex 1,

France. Telephone 0033473

6258 80; fax 003347362

58 81; email

fdurif@chu-clermontferrand.fr

Received 6 August 1998 and in revised form

16 January 1999

Accepted 19 January 1999 day, using sustained release levodopa, and adding dopamine agonists usually temporarily improves motor complications, which can reappear and worsen when the disease progresses.

Surgical treatment may be proposed to patients not satisfactorily improved by medical treatment. Recently, there has been a resurgence of interest in pallidotomy for the treatment of advanced Parkinson's disease. This surgical procedure dramatically reduces contralateral LIDs but also improves all cardinal parkinsonian signs such as rest tremor, rigidity, bradykinesia, and gait dysfunction..$^{2-9}$ Equivalent results have recently been shown with chronic high frequency deep brain stimulation, which is an alternative surgical nonlesional treatment for Parkinson's disease. ${ }^{10-13}$

Currently, the optimal lesion site of pallidotomy or pallidal stimulation remains uncertain. ${ }^{14}$ In the early 1950 s neurosurgeons investigated lesion of the anterodorsal region in the internal portion of the globus pallidus (Gpi) ${ }^{1516}$ In 1960, Svennilson et al ${ }^{17}$ reported that stereotactic lesions in the ventroposterolateral pallidum markedly improved the clinical results. Since the recent surgical reassessment of pallidotomy by Laitinen et $a l,{ }^{2}$ neurosurgeons have performed pallidotomy or high frequency deep brain stimulation in the ventroposterior GPi. However, a recent report has shown a dramatic improvement of cardinal parkinsonian signs in a patient after bilateral chronic anterior pallidal stimulation. ${ }^{10}$

In an attempt to confirm the results of this pilot study and thus to re-evaluate the anterior target in GPi, we assessed the motor effects of acute electrical stimulation on different parts of the anterior GPi on parkinsonian signs and on LID in patients after implantation of quadripolar electrodes. We also evaluated the effects of chronic anterior pallidal stimulation in patients after a 6 month period.

\section{Methods}

PATIENTS

Six patients (four men, two women) fulfilling the requirements for the United Kingdom Parkinson's Disease Society Brain Bank ${ }^{18}$ of mean age (SEM) 64 (3) years were included after acceptance of the study by the ethics committee of Auvergne University (table 1). These patients gave written consent to their participation in this study. The mean duration of the disease was 15 (2) years and the mean duration of the treatment was 12 (2) years. Before surgery, the levodopa daily dose (plus peripheral decarboxylase inhibitor) was 1200 (260) $\mathrm{mg}$. Four of the patients received a dopamine 
Table 1 Patient's characteristics at baseline

\begin{tabular}{|c|c|c|c|c|c|c|c|c|}
\hline \multirow[b]{2}{*}{ Patient } & \multirow[b]{2}{*}{ Age (y) } & \multirow[b]{2}{*}{ Sex } & \multirow{2}{*}{$\begin{array}{l}\text { Disease } \\
\text { duration } \\
(y)\end{array}$} & \multirow{2}{*}{$\begin{array}{l}\text { Dosage of } \\
\text { levodopa } \\
\text { (mg/day) }\end{array}$} & \multicolumn{2}{|c|}{$\begin{array}{l}\text { Motor part of } \\
\text { UPDRS }\end{array}$} & \multicolumn{2}{|c|}{ Hoehn and Yahr } \\
\hline & & & & & off & on & off & on \\
\hline 1 & 73 & $\mathrm{~F}$ & 13 & 1000 & 29 & 10 & 4 & 3 \\
\hline 2 & 66 & $\mathrm{~F}$ & 10 & 1050 & 41 & 6.5 & 5 & 2 \\
\hline 3 & 66 & $\mathrm{~F}$ & 20 & 800 & 42 & 15 & 4 & 3 \\
\hline 4 & 65 & $\mathrm{~F}$ & 15 & 1050 & 30 & 9 & 4 & 3 \\
\hline 5 & 51 & M & 10 & 2500 & 35 & 7 & 4 & 2 \\
\hline 6 & 65 & M & 25 & 900 & 38 & 5 & 5 & 2 \\
\hline Mean & $64(3)$ & & $15(2)$ & $1200(260)$ & $36(2)$ & $9(1)$ & $4.3(0.2)$ & $2.5(0.2)$ \\
\hline
\end{tabular}

Values in parentheses are SEM.

agonist, one patient received tolcapone, and two patients received subcutaneous injections of apomorphine. Despite optimisation of antiparkinsonian treatment, severe motor fluctuations and monophasic and diphasic levodopa induced dyskinesias still persisted in all of the patients.

Their mean baseline unified Parkinson's disease rating scale (UPDRS) (parts I+II+III) was 60 (6). ${ }^{19}$ All patients had an excellent response to levodopa (mean improvement 72 (33)\% (table 1)). The mean duration of LIDs was 2.5 (1.0) hours and their severity was 3.0 (0.6) (items 32-33 from part IV of the UPDRS). The mean duration of daily time spent in the "off state was 1.6 (0.8) hours (item 39 from part IV of the UPDRS). All patients had no dementia (mean mental status of Folstein 28 (1). Presurgical MRI performed in the 3 months before surgery was normal.

NEUROSURGICAL PROCEDURE

A week before surgery, an MRI obtained in stereotactic conditions (sMRI) using a stereotactic frame (Leksell model G, Elekta Instruments, Stockholm, Sweden) with a repositioning system (Elekta Instruments, Stockholm, Sweden) was carried out. An iodoventriculography was also performed on the first five patients. The sMRI (Siemens Magnetom 1 Tesla, matrix $256 \times 256)$ consisted of three sequences of orthogonal plans with contiguous slices $3 \mathrm{~mm}$ thick. T2 weighted images ( $T R=2500 \mathrm{~ms}, \mathrm{TE}=20 \mathrm{~ms}$ ) were achieved in a frontal and an axial plane and $\mathrm{T} 1$ weighted images ( $T R=450 \mathrm{~ms}, \mathrm{TE}=15 \mathrm{~ms}$ ) in a sagittal plane. Images were then transferred to a workstation. We used a stereotactic software package (Brainscan, Brainlab, Germany) to locate the brain structures in sMRI spaces. The target of the GPi was the vertex of the nucleus facing the knee of the internal capsule. The software calculated the coordinates of the target and the simulated electrode trajectory. A week later, the stereotactic frame was repositioned. A semimicroelectrode (FHC, Brunswick, USA) was advanced along the selected trajectory given by the software and stimulation $(130 \mathrm{~Hz}$, pulse width $60 \mu \mathrm{s}, 0-10 \mathrm{~mA}$ ) was performed millimeter by millimeter starting $10 \mathrm{~mm}$ above the target. Clinical and side effects of the stimulation were evaluated by a neurologist (FD) unaware of the stimulation condition. We used tremor, rigidity (wrist, elbow, ankle), and bradykinesia (pronosupination of the hand, thumb-index tapping) subjective assessments (improvement or aggravation percentage from the prestimulation status) to evaluate the clinical effect of stimulation. The site chosen for the definitive electrode placement was determined during stimulation by the maximum improvement of contralateral upper and lower limb tremor and rigidity, and upper limb bradykinesia. A chronic deepbrain stimulation quadripolar electrode (3387, Medtronic, Minneapolis, $\mathrm{MN}$ ) was implanted to replace the semi-microelectrode directed toward the target. The electrode had four contacts $1.5 \mathrm{~mm}$ long with a distance of $1.5 \mathrm{~mm}$ and with an external diameter of $1.3 \mathrm{~mm}$. Stereotactic $x$ ray film controls were performed during the procedure to verify that there was no electrode shift. One electrode on each side was implanted during the same procedure for five patients. All patients had a postoperative MRI a week after the surgical procedure before the implantation of the programmable stimulator (Itrel II, Medtronic) in the subclavicular area.

\section{PATIENT ASSESSMENTS}

Clinical effect of postoperative acute stimulation

The effect of electrical stimulation via the four contacts of the electrode was assessed on the parkinsonian signs and on LIDs within the 12 days after the surgical procedure.

Parkinsonian signs were assessed in the off condition after interruption of the antiparkinsonian treatment for at least 12 hours using items from the UPDRS part III: contralateral limb rigidity, contralateral bradykinesia (thumb-index tapping), and contralateral upper and lower limb rest tremor. The clinical effect of electrical stimulation for each electrode (six patients, 11 electrodes) was evaluated by using improvement or aggravation percentage from clinical evaluations performed without stimulation. The LIDs were evaluated in the "on" state during two acute suprathreshold levodopa challenges on 2 consecutive days using a subjective scale $(0=$ no abnormal movement; $4=$ movement resulting in severe disability) on the four limbs, on the trunk, the neck and face (maximum score 28), during rest and after an activation task (speaking aloud). ${ }^{20}$

The stimulation mode was unipolar with a negative electrode contact. The pulse width and the frequency of the stimulation current were respectively kept at $130 \mathrm{~Hz}$ and $60 \mu \mathrm{s}$. The voltage amplitude was progressively increased from 0 to $5 \mathrm{~V}$. Clinical evaluation was performed at each voltage step. Before each assessment, a stimulation period of at least 5 minutes (parkinsonian symptoms) or at least 15 minutes (evaluation of LIDs) was used. A 10 minute period without stimulation was allowed before evaluation of another contact, showing that the clinical indices studied returned to the baseline.

\section{Clinical effect of chronic stimulation}

Patients were evaluated according to the core assessment program for intracerebral transplantation (CAPIT) protocol. ${ }^{21}$ The evaluations, which were videotaped, were rated during the off state and during the best on state, as agreed by the patient and physician. The clinical evaluation was performed before 

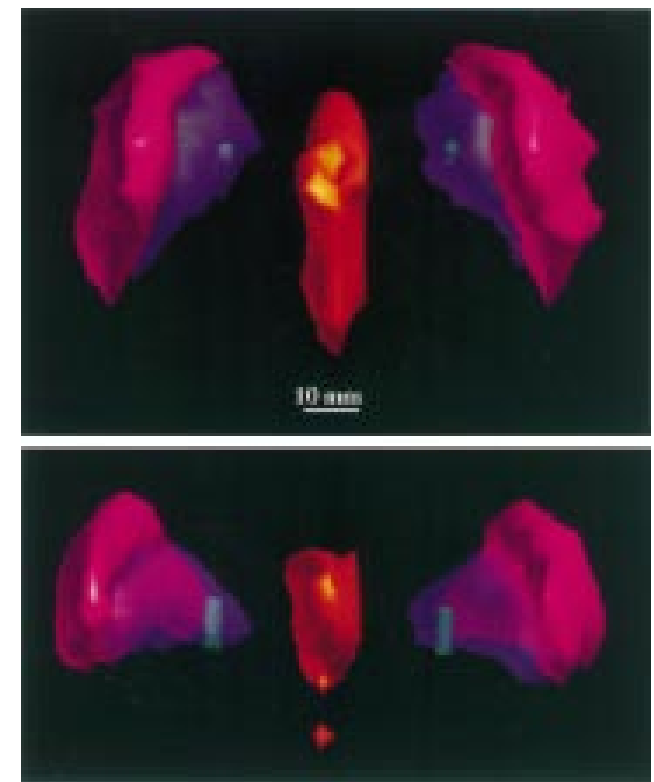

Figure 1 Three dimensional reconstruction of the right and left globus pallidus (GP) and active contacts from MRI T2 weighted images of one patient. The GP is represented by purple and the putamen by pink. The third ventricle is represented by orange. GPs are transparent to allow visualisation of the distal contacts and the active contacts (contact 2) 6 months after the surgery. Only the centre of the contacts is represented (located on the extremities of the green segments). (Upper, dorsal view; lower, posterior view.)

surgery and then on the 1st, 3rd, and 6th month in on-off drug conditions and on-off stimulation conditions. Furthermore, patients kept diaries for at least 3 days before each clinical assessment in which they noted the diurnal time spent with good motor function (on state), poor motor function (off state), and motor function accompanied by incapacitating

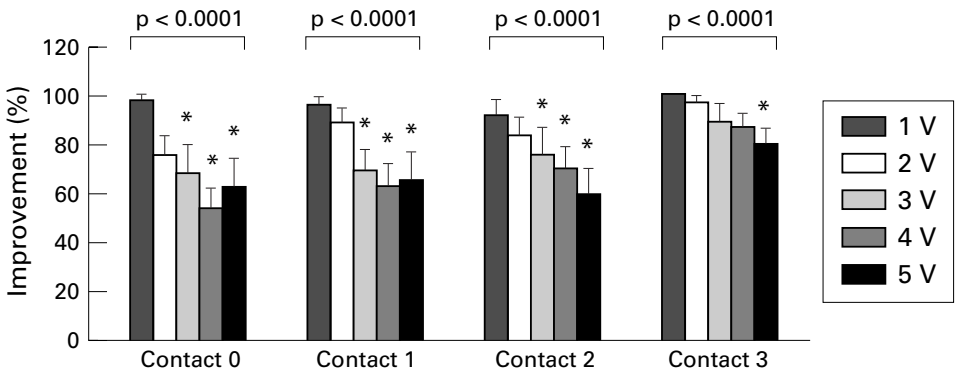

Figure 2 Effect of acute postoperative stimulation on contralateral rigidity for each contact of electrodes $(n=11) ; 100 \%$ represents the rigidity score before stimulation. The effect of amplitude voltage on every contact was analysed by ANOVA with repeated measures. ${ }^{\star} p<0.05 v$ clinical evaluation before stimulation (Newman-Keuls tests).

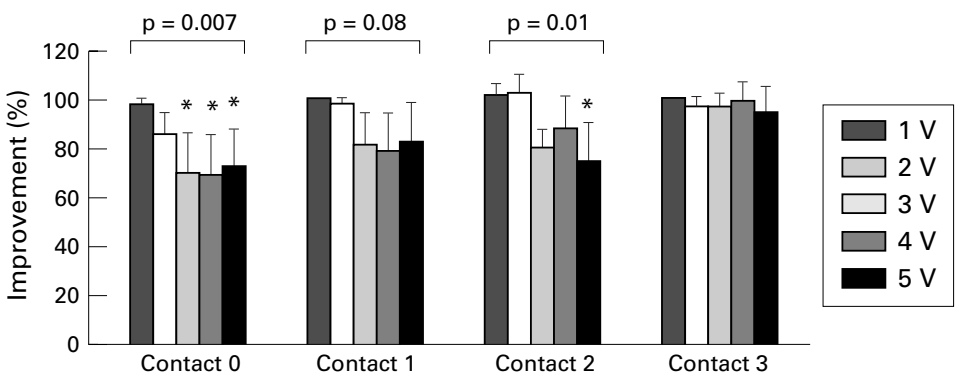

Figure 3 Effect of acute postoperative stimulation on contralateral bradykinesia for each contact of electrodes $(n=11) ; 100 \%$ represents the bradykinesia score before stimulation. The effect of amplitude voltage on every contact was analysed by ANOVA with repeated measures. ${ }^{\star} p<0.05 v$ clinical evaluation before stimulation (Newman-Keuls tests). involuntary movements (on state with dyskinesias). Chronic stimulation was adapted from the results that were obtained during the acute assessment period with a view to reducing the duration and the severity of LIDs, and the time spent in the off state. For each patient, stimulation indices (amplitude voltage, pulse width, frequency) were adapted every day for 2 weeks and then every month for a period of 3 months in relation with their motor status.

\section{LOCATION OF THE ELECTRODE CONTACTS}

Coordinates of the contacts which gave the best clinical results during the peroperative assessment (distal contact) and 6 months after the surgical procedure were determined from the control radiograph performed at the end of the surgical procedure. The coordinates of all contacts for the six patients were automatically placed within the pallidum, which was reconstructed for each patient in three dimensions from frontal and horizontal preoperative sMRI slices with stereotactic software (fig 1). The distances between the centre of each contact and the medial, dorsal, and ventral boundaries of the pallidum were measured for all patients (bilaterally for five patients). Furthermore, for the first five patients in which a ventriculography was performed, we also calculated the location of the distal contacts and the contacts which gave the best clinical results 6 months after the surgical procedure with reference to the ventriculographic landmarks of Talairach et $a l^{22}$ : the laterality from the median sagittal plane of the third ventricle, the anterior position from the midpoint of the intercommissural line (Mic), and the vertical position in relation to the intercommissural line (Icl) (above or below).

\section{STATISTICAL ANALYSIS}

Values were expressed as mean (SEM). Rest tremor was not analysed because only one patient had a stable tremor in the off state. Contralateral and ipsilateral dyskinesias were calculated from the sum of the lower and upper limbs, which were items from the dyskinesia scale. The effect of the voltage amplitude for each contact electrode and for each electrode on contralateral parkinsonian signs (rigidity and bradykinesia), and on contralateral and ipsilateral LIDs, was analysed using analyses of variance (ANOVAs) with repeated measures in which the repetition factor was the voltage amplitude from 0 to $5 \mathrm{~V}$. When the ANOVA showed a significant difference, the NewmanKeuls test was performed. According to the distribution of data, a Wilcoxon signed rank test and a paired Student's $t$ test were used to compare assessment performed before surgery and 6 months afterwards. Significance was declared at $\mathrm{p} \leqslant 0.05$

\section{Results}

LOCATION OF THE ELECTRODE CONTACTS Location in relation to the boundaries of the pallidum

The mean distances (mean of both sides) from the distal active contacts to the boundaries of the pallidum were respectively to the medial 


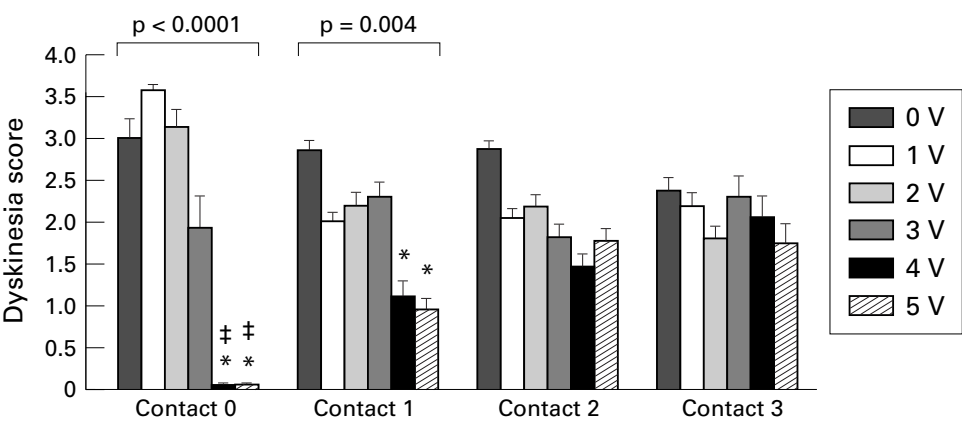

Figure 4 Effect of acute postoperative stimulation on contralateral dyskinesia assessed during an activation task (speaking aloud) for each contact of electrodes $(n=11)$. The effect of amplitude voltage on every contact was analysed by ANOVA with repeated measures. ${ }^{\star} p<0.05 v$ clinical evaluation without stimulation (Newman-Keuls tests). $\ddagger p<0.05 v 1 \mathrm{~V}$, $2 \mathrm{~V}$, and $3 \mathrm{~V}$ amplitude (Newman-Keuls tests).

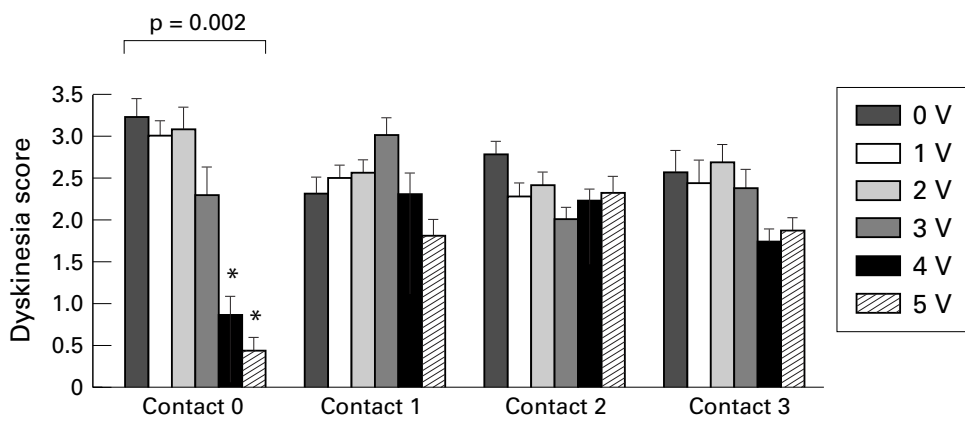

Figure 5 Effect of acute postoperative stimulation on ipsilateral dyskinesia assessed during an activation task (speaking aloud) for each contact of electrodes $(n=11)$. The effect of amplitude voltage on every contact was analysed by ANOVA with repeated measures. ${ }^{*} p<0.05 v$ clinical evaluation without stimulation (Newman-Keuls tests).

boundary of the pallidum $2.4(0.7) \mathrm{mm}$, to the dorsal boundary $4.2(0.5) \mathrm{mm}$, and to the ventral boundary $0.4(0.4) \mathrm{mm}$. The mean distance from the active contacts 6 months after the surgery (contact 1 bilaterally in three patients; contacts 2 bilaterally (apart for one patient with unilateral stimulation) in three patients) to the boundaries of the pallidum were respectively to the medial boundary $2.5(0.6) \mathrm{mm}$, to the dorsal boundary $2.5(0.5) \mathrm{mm}$, and to the ventral boundary 4.2 (0.4) $\mathrm{mm}$. The mean distances from the proximal contact 3 were respectively to the medial boundary of the pallidum $-0.8(1.5) \mathrm{mm}$ (medial to the medial boundary), to the dorsal boundary -0.1 (0.6) $\mathrm{mm}$ (above the dorsal boundary), and to the ventral boundary $8.1(0.6) \mathrm{mm}$.

Location in relation to stereotactic landmarks For the distal contacts, the mean laterality was $15.3(0.4) \mathrm{mm}$, the mean anterior position was $9.3(0.6) \mathrm{mm}$ in front of the Mic, and the vertical position was $0.8(0.9) \mathrm{mm}$ above the Icl. For the active contacts 6 months after the surgery, the mean laterality was $15.4(0.4) \mathrm{mm}$, the mean anterior position was $11.5(0.6) \mathrm{mm}$ in front of the Mic, and the vertical position was $2.1(0.3) \mathrm{mm}$ above the Icl.

EFFECT OF POSTOPERATIVE ACUTE STIMULATION Parkinsonian signs (rigidity and bradykinesia)

Analyses of variance showed a significant improvement of rigidity when stimulation was applied through the four contacts: contact 0 (distal contact), $F(8)=11.6, \mathrm{p}<0.0001$; contact $1, F(8)=9.8, \mathrm{p}<0.0001$; contact $2, F(8)=8.4$, $\mathrm{p}<0.0001$; contact 3 (proximal contact),
$F(8)=5.6, \quad \mathrm{p}<0.0001$. Newman-Keuls tests showed a significant improvement $(p<0.05)$ of rigidity: (1) at $3 \mathrm{~V}, 4 \mathrm{~V}$, and $5 \mathrm{~V}$ amplitude compared with rigidity evaluated without stimulation when electrical stimulation was applied through contacts 0,1 , and $2 ;(2)$ at $5 \mathrm{~V}$ amplitude when stimulation was applied through contact 3 . For each contact, rigidity improved progressively with the voltage and reached a plateau at 3 or $4 \mathrm{~V}$. The maximum percentage improvement decreased when stimulation was applied from contact 0 to contact 3: at optimal amplitude voltage, the rigidity percentage improvement was $47 \%$ (contact 0), 38\% (contact 1), 30\% (contact 2), and 20\% (contact 3) (fig 2).

Analyses of variance also showed significant improvement of bradykinesia only at contact 0 $(F(8)=3.7, \mathrm{p}=0.007)$ and contact $2(F(8)=3.4$, $\mathrm{p}=0.01)$. Newman-Keuls tests showed a significant improvement $(p<0.05)$ : (1) At $3 \mathrm{~V}, 4 \mathrm{~V}$, and $5 \mathrm{~V}$ amplitude compared with bradykinesia evaluated without stimulation when electrical stimulation was applied on the contact $0 ;(2)$ at $5 \mathrm{~V}$ amplitude when stimulation was applied on contact 2 . At optimal amplitude voltage, the maximum improvement found was $32 \%$ (contact 0 ), 22\% (not significant) (contact 1 ), and $26 \%$ (contact 2 ). No clinical effect was detectable when stimulation was applied through contact 3 (fig 3). An aggravation of contralateral bradykinesia by $30 \%$ was found when stimulation was applied through the four contacts with amplitude voltage higher than 3 $\mathrm{V}$ for two of the electrodes tested.

In one patient, stimulation on contacts 0,1 , and 2 led to a disappearance of contralateral off foot dystonia which reappeared when stimulation was stopped.

\section{Levodopa induced dyskinesias}

Analyses of variance showed a significant improvement of contralateral LIDs when stimulation was at contact $0(F(6)=11.1$, $\mathrm{p}<0.0001)$ and contact $1 \quad(F(6)=4.15$, $\mathrm{p}=0.004)$. Newman-Keuls tests showed a significant improvement $(p<0.05)$ of contralateral LIDs at $4 \mathrm{~V}$ and $5 \mathrm{~V}$ amplitude compared with contralateral LIDs evaluated without stimulation on contacts 0 and 1 . There was also a significant improvement $(p<0.05)$ of contralateral LIDs at $4 \mathrm{~V}$ and $5 \mathrm{~V}$ amplitude compared with $1 \mathrm{~V}, 2 \mathrm{~V}$ and $3 \mathrm{~V}$ amplitude when stimulation was on contact 0 .

For all of the patients, when stimulation was applied through distal contact 0 , contralateral LIDs progressively disappeared when the amplitude voltage increased with a maximum improvement of $95 \%$ at $4 \mathrm{~V}$. In three patients (five electrodes), the parkinsonian signs progressively appeared and worsened when the amplitude voltage was higher than $4 \mathrm{~V}$. On contact 1 , the maximum improvement of LIDs was $66 \%$ at $5 \mathrm{~V}$, without any worsening of parkinsonian signs. The LIDs reappeared with latency within 0 to 10 minutes when stimulation was stopped on the two lower contacts ( 0 and 1). No clear clinical effect was seen when stimulation was applied on contacts 2 and 3, from 0 to $5 \mathrm{~V}$ (fig 4 ). 
Table 2 Stimulation indices 6 months after the surgical procedure

\begin{tabular}{|c|c|c|c|c|c|c|c|c|}
\hline \multirow[b]{2}{*}{ Patient } & \multicolumn{4}{|c|}{ Right pallidum } & \multicolumn{4}{|c|}{ Left pallidum } \\
\hline & Contact & $\begin{array}{l}\text { Amplitude } \\
\text { voltage }(V)\end{array}$ & $\begin{array}{l}\text { Frequency } \\
(\mathrm{Hz})\end{array}$ & $\begin{array}{l}\text { Pulse width } \\
(\mu s)\end{array}$ & Contact & $\begin{array}{l}\text { Amplitude } \\
\text { voltage }(V)\end{array}$ & $\begin{array}{l}\text { Frequency } \\
(\mathrm{Hz})\end{array}$ & $\begin{array}{l}\text { Pulse width } \\
(\mu s)\end{array}$ \\
\hline 1 & 2 & 4 & 130 & 60 & - & - & - & - \\
\hline 2 & 1 & 2.2 & 130 & 90 & 1 & 2.0 & 130 & 90 \\
\hline 3 & 1 & 3.5 & 130 & 60 & 1 & 3.8 & 185 & 90 \\
\hline 4 & 1 & 2.3 & 130 & 90 & 1 & 3.2 & 185 & 90 \\
\hline 5 & 2 & 3.5 & 130 & 60 & 2 & 3.5 & 185 & 90 \\
\hline 6 & 2 & 3.8 & 130 & 90 & 2 & 3.8 & 130 & 90 \\
\hline
\end{tabular}

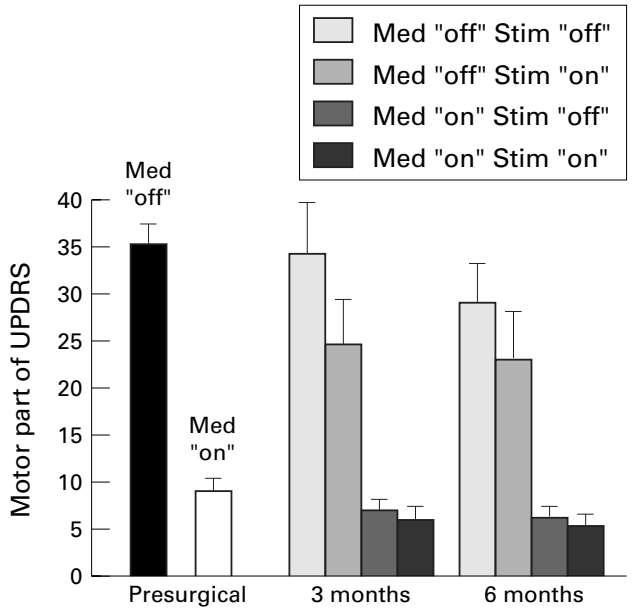

Figure 6 Effect of stimulation on motor part of UPDRS 3 and 6 months after surgical procedure (med=medication; stim=stimulation).

Ipsilateral LIDs were also improved when stimulation was applied on contact 0 as shown by ANOVAs $(F(6)=4.7, \mathrm{p}=0.002)$. NewmanKeuls tests showed a significant improvement $(\mathrm{p}<0.05)$ of ipsilateral LIDs at $4 \mathrm{~V}$ and $5 \mathrm{~V}$ amplitude compared with ipsilateral LID evaluated without stimulation, and at $1 \mathrm{~V}$ and 2 $\mathrm{V}$ amplitude. No significant effect was shown when stimulation was applied on contacts 1,2 , and 3 (fig 5).

Table 3 Motor evaluations at baseline and follow up 6 months after the surgery

\begin{tabular}{|c|c|c|c|c|c|c|}
\hline \multirow[b]{3}{*}{ Patient } & \multicolumn{3}{|c|}{ Medication off } & \multicolumn{3}{|c|}{ Medication on } \\
\hline & \multirow[b]{2}{*}{ Baseline } & \multicolumn{2}{|l|}{ Follow up } & \multirow[b]{2}{*}{ Baseline } & \multicolumn{2}{|l|}{ Follow up } \\
\hline & & $\begin{array}{l}\text { Stimulation } \\
\text { off }\end{array}$ & $\begin{array}{l}\text { Stimulation } \\
\text { on }\end{array}$ & & $\begin{array}{l}\text { Stimulation } \\
\text { off }\end{array}$ & $\begin{array}{l}\text { Stimulation } \\
\text { on }\end{array}$ \\
\hline 1 & 29 & 43 & 34 & 10 & 7 & 6 \\
\hline 2 & 41 & 35 & 32 & 6.5 & 5 & 4 \\
\hline 3 & 42 & 22 & 8 & 15 & 5.5 & 3.5 \\
\hline 4 & 30 & 19 & 13.5 & 9 & 6 & 6 \\
\hline 5 & 35 & 37 & 37 & 7 & 11 & 10 \\
\hline 6 & 38 & 18.5 & 13 & 5 & 2 & 2 \\
\hline Mean & $36(2)$ & $29(4) \mathrm{p}=0.27$ & 23 (5) $\mathrm{p}=0.09$ & $9(1)$ & 6 (1) $p=0.18$ & 5 (1) $\mathrm{p}=0.13$ \\
\hline
\end{tabular}

$\mathrm{p}$ Values were calculated $v$ evaluation at baseline.

Values in parentheses are SEM.

Table 4 Motor fluctuations at baseline and 6 months after surgery

\begin{tabular}{llll}
\hline & Baseline & Follow up & p Value \\
\hline Duration of dyskinesias & $2.5(0.5)$ & $1.0(0.5)$ & 0.04 \\
Severity of dyskinesias & $3.0(0.3)$ & $1.5(0.5)$ & 0.05 \\
Duration of "off" period & $1.7(0.6)$ & $0.8(0.2)$ & 0.04 \\
Duration of dyskinesias† (hours) & $5.2(0.9)$ & $3.0(0.9)$ & 0.02 \\
Duration of "best on" $\dagger$ (hours) & $8.6(0.5)$ & $11.8(0.9)$ & 0.09 \\
Duration of "off" period† (hours) & $6.5(0.6)$ & $2.8(0.7)$ & 0.02 \\
\hline
\end{tabular}

Values for baseline and follow up are means (SEM).

^From items of UPDRS part IV.

†Calculated from diaries.
EFFECT OF CHRONIC STIMULATION

For the 3 months after the surgical procedure, stimulation was changed from lower distal contacts to more upper proximal contacts in relation to the motor status of patients. Six months after the surgery, stimulation was applied on contact 1 for three patients and on contact 2 for the remaining three patients. The amplitude voltages were not changed compared with the effective values obtained during the acute postoperative study (table 2). Four patients reported a dramatic improvement of motor complications and two patients had a marked decrease of dyskinesia severity. Compared with preoperative values evaluated in the off condition, bilateral chronic stimulation led to a mean improvement of the UPDRS score (parts I+II+III) by $25 \%$. The motor part of UPDRS improved by $36 \%$ (table 3, fig 6). Contralateral bradykinesia evaluated with arm movement timed tasks from CAPIT was also improved by $18 \%(\mathrm{p}<0.05)$ (movements between two points), 30\% $(p=0.06) \quad$ (finger dexterity), and $30 \%$ (pronation-supination; not significant). Gait disturbance improved by $20 \%$ (not significant). The mean Hoehn and Yahr staging improved by $20 \%(p<0.05)$. Compared with clinical evaluation performed in the on state, bilateral stimulation did not change UPDRS scores, arm timed tasks, and gait disturbance.

The mean daily duration in the off state decreased by $52 \%(p<0.05)$ (item 39 from the IV of UPDRS score). The mean duration of LIDs decreased by $68 \%(\mathrm{p}<0.05)$ and their severity by $53 \%(p=0.05)$ (items $32-33$ from part IV of the UPDRS score). As measured by patient self assessment, the diurnal time spent in the on state without severe LIDs increased by $37 \%(p<0.05)$. Similarly, the time spent in the on state with disabling LIDs, and in the off state respectively decreased by $42 \%(\mathrm{p}=0.09)$ and $57 \%(\mathrm{p}<0.05)$ (table 4$)$.

There was no significant change of total daily levodopa dose (mean daily levodopa dose before surgery $1200 \mathrm{mg}$, 6 months after surgery $1275 \mathrm{mg}$ ) and number of levodopa daily doses. One patient stopped subcutaneous apomorphine injections.

After surgery, one patient developed a transient aseptic hyperthermia within 24 hours. Another patient developed a severe depression within the month after surgery which improved remarkably after chronic clomipramine treatment. Acute and chronic stimulation led to transient side effects such as paraesthesia, nausea, and thoracic oppression, which were mainly related to the amplitude voltage. Postoperative MRI was normal. 


\section{Discussion}

EFFECT OF POSTOPERATIVE ACUTE STIMULATION In this study, postoperative acute electrical stimulation in the anterior GPi induced a marked improvement of cardinal parkinsonian signs (akinesia and rigidity) when patients were in the off state, and led to a dramatic decrease in severity of contralateral and ipsilateral LIDs when patients were evaluated in the on state. At a higher voltage, blockage of the levodopa effect leading to reappearance of parkinsonian signs was found in three patients, as already reported by Krack et $a l^{13}$ The effect of stimulation on rigidity, bradykinesia, and on LIDs predominated when stimulation was applied on the ventral contacts, and then progressively decreased when stimulation was applied on the dorsal contacts. These results are at variance from those of Bejjani et $a l^{3}$ who reported that acute stimulation in the posteroventral GP, using the same electrode as in our study, had a striking, different effect on parkinsonism and dyskinesia when applied to two different targets of the GPi. The stimulation on the dorsal part of the Gpi led to an improvement of parkinsonian signs when patients were in the off state whereas stimulation applied on the ventral part of the GPi led to a worsening bradykinesia when patients were in the off state, but suppressed LIDs when patients were in the on state. Krack et al also reported that stimulation on the ventral part of GPi induced an improvement of rigidity whereas stimulation on the dorsal part led to a moderate improvement of akinesia. ${ }^{13}$

Our different results could be explained by the fact that we have implanted electrodes more anteriorly and medially in the GPi. The volume of neural tissue affected by stimulation is probably in the order of $\mathrm{mm}^{3}$. Thus, the effect of stimulation probably predominates in the anteromedial part of the GPi although the diffusion of current can also slightly influence the posteroventral part. In our study, the distal contacts were on average $6 \mathrm{~mm}$ in front of, 6 $\mathrm{mm}$ above, and $5 \mathrm{~mm}$ medial to the target of Laitinen et $a l^{2}$ and thus corresponds to the classic anterior target for pallidotomy. ${ }^{15}$ Furthermore, according to the stereotactic coordinates of Talairach et $a l^{22}$ the active contacts projected into the internal part of the GPi, and into the ansa lenticularis. Moreover, the superimposition of active contacts within the pallidum showed that the electrodes are placed in the anteromedial part of the pallidum. According to the distances from the contacts to the boundaries of the pallidum on one hand, and the size of the GPi on the other, ${ }^{24}$ it may be assumed that the distal contacts were on the ventral boundary of the GPi and the contacts 1 and 2 were within the GPi (fig 1 ). The fact that stimulation on the proximal contact 3 does not induce any significant change of bradykinesia and LIDs, relates to their anatomical location, situated above the Gpi in the anterior part of the internal capsule.

The anteromedial part of the GPi, which corresponds to the ventral pallidum, is crossed by a greater number of fibres at the origin of the outflow pathways, given the convergence of the anatomical structure to GPi output. These pathways (ansa lenticularis, lenticular fasciculus) are mainly localised above the optic tract and medially to the pallidum and project to the thalamus throughout the internal capsule. ${ }^{25}$ Thus, stimulation on the distal contact probably influenced the ansa lenticularis, which was localised on the ventral surface of the pallidum.

Although the effect of electrical stimulation is largely unknown, it is assumed that stimulation induced a direct or indirect neuronal inactivation, as shown by electrophysiological studies in rats. ${ }^{26}$ The improvement of parkinsonian signs by stimulation on the distal contact when patients were in the off state may be explained by inhibition of the GPi, which is hyperactive after the striatal dopamine depletion seen in Parkinson's disease. The decrease of GPi activity disinhibits the pallidal relay nuclei of the thalamus, which leads to a disinhibition of thalamocortical neurons resulting in an improvement of parkinsonian signs. ${ }^{27-29}$ Such results have been shown in PET studies in parkinsonian monkeys and in parkinsonian patients in which pallidal stimulation and pallidotomy restore the regional cerebral blood flow in the frontal cortex. ${ }^{30}{ }^{31}$ Otherwise, the improvement of LIDs by stimulation on the distal contact is hard to explain by the classic model of the basal ganglia because LIDs may be considered to be linked to GPi hypoactivity. ${ }^{32-34}$ However, a recent electrophysiological study performed on parkinsonian monkeys with dyskinesias suggests that dyskinesias could also result from an imbalance of neuronal activity within the GPi, where hypoactive neurons were surrounded by hyperactive or unresponsive neurons. ${ }^{35}$ Thus stimulation of the medial $\mathrm{GPi}$ could reestablish a normal balance of activity between the different neuronal networks in the GPi leading to an improvement of LIDs.

EFFECT OF CHRONIC STIMULATION

In our study, chronic stimulation in the anterior GPi led to an improvement of parkinsonian signs and LIDs. Furthermore, stimulation significantly increases the daily duration of the on state and reduces the time spent with severe dyskinesias in this state. Moreover, stimulation significantly reduces the time spent in the off state. The fact that our chronic results are close to those reported in other studies in which stimulation was in the posteroventral portion of the GPi, suggests that the anterior target could be as effective as the posteroventral part of the GPi in advanced Parkinson's disease. ${ }^{11-13}$ Compared with the ventrolateral $\mathrm{GPi}$, one of the advantages of the anterior target is that it is easily located by using stereotactic MRI.

Compared with the clinical effect found during the acute assessment, the best results of chronic stimulation occured when stimulation was applied on more proximal contacts, which were more dorsal than the distal contacts. One of the possible explanations could be that chronic stimulation on the distal contacts when patients are in the on state decreases 
LID but also induces a blockage effect of levodopa at a lower voltage than during the acute evaluation, requiring stimulation to be moved to the proximal contacts. These results could indicate that the stimulation condition (acute $v$ chronic) leads to different changes in the activity of GPi or alternatively induces tolerance phenomena.

In our study, there was no permanent morbidity associated with the surgical procedure. The side effects were in relation to the stimulation condition and always reversible by the reduction of the amplitude voltage. Such results have been reported in other studies showing that the procedure of chronic pallidal stimulation is neurologically safe $\mathrm{f}^{36-38}$ compared to the pallidotomy in which the incidence of long term complications was noted in $10 \%$ in a study comprising 138 patients. ${ }^{39}$

Our chronic results are close to those reported when chronic stimulation was applied in the posteroventral part of the $\mathrm{GPi}$, in which reduction of the motor score of UPDRS by $30-40 \%$ and an improvement of dyskinesia by $60-70 \%$ was found. ${ }^{37}{ }^{38}$ However, chronic stimulation of the subthalamic nucleus could give better results than stimulation of GPi whatever the site of stimulation because a recent retrospective study comparing stimulation of subthalamic nucleus or GPi (posteroventral part) in young patients has shown a significant higher improvement of the motor score of the UPDRS, and a significant reduction of treatment when stimulation was applied on subthalamic nucleus. ${ }^{38}$ However, such a result needs to be confirmed by randomised trials.

In summary, acute anteromedial GPi stimulation applied to the distal part of the nucleus induces an improvement of parkinsonian signs when patients are in the off state and of dyskinesia when they are in the on state. Chronic results show that this is an effective treatment for advanced Parkinson's disease with benefit sustained for at least 6 months, which suggests that the procedure will be effective for years. A survey of patients every 6 months is now in progress. However, this surgical procedure needs to be evaluated with a larger number of patients and to be compared with other neurosurgical treatments such as ventrolateral $\mathrm{GPi}$ and subthalamic stimulations. $^{38}$ 40-43

1 Marsden CD, Parkes JD, Quinn N. Fluctuations of disability in Parkinson's disease-clinical aspects. In: Marsden CD ity in Parkinson's disease-clinical aspects. In: Marsden CD, Fahn S, eds.

2 Laitinen LV, Bergenheim AT, Hariz MI. Leksell's posteroventral pallidotomy in the treatment of Parkinson's disease. f Neurosurg 1992;76:53-61.

3 Dogali M, Fazzini E, Kolodny E, et al. Stereotactic ventral pallidotomy for Parkinson's disease. Neurology 1995;45: 753-61.

4 Iacono R, Shima F, Lonser R, et al. The results, indications, and physiology of posteroventral pallidotomy for patients
with Parkinson's disease. Neurosurgery 1995;36:1118-25.

5 Sutton JP, Couldwell W, Lew MF, et al. Ventroposterior medial pallidotomy in patients with advanced Parkinson's disease. Neurosurgery 1995;36:1112-7.

6 Baron MS, Vitek JL, Bakay RAE, et al. Treatment of advanced Parkinson's disease by posterior GPi pallidotomy: 1-year results of a pilot study. Ann Neurol 1996;40:355-66.

7 Johanson F, Malm J, Nordth E, et al. Usefullness of pallidotomy in advanced Parkinson's disease. $7 \mathrm{Neurol} \mathrm{Neu}$ rosurg Psychiatry 1997;62:125-32.
8 Lang AE, Lozano AM, Montgomery E, et al. Posteroventral medial pallidotomy in advanced Parkinson's disease. $N$ Engl f Med 1997;337:1036-42.

9 Uitti RJ, Wharen RE, Turk MF, et al. Unilateral pallidotomy for Parkinson's disease: comparison of outcome in younger versus elderly patients. Neurology 1997;49:1072-7.

10 Iacono RP, Lonser RR, Maeda G, et al. Chronic anterior pallidal stimulation for Parkinson's disease. Acta Neurochir (Wein) 1995;137:106-12

11 Pahwa R, Wilkinson S, Smith D, et al. High-frequency stimulation of the globus pallidus for the treatment of Parkinson's disease. Neurology 1997;49:249-53.

12 Gross C, Rougier A, Guehl D, et al. High-frequency stimulation of the globus pallidus internalis in Parkinson's lation of the globus pallidus internalis in Parkinson's

13 Krack P, Pollak P, Limousin P, et al. Opposite motor effects of pallidal stimulation in Parkinson's disease. Ann Neurol 1998;43:180-92.

14 Bakay RAE, Delong MR, Vitek JL. Posteroventral pallidotomy for Parkinson's disease. If Neurosurg 1992;77: $487-8$.

15 Guiot G, Brion S. Traitement des mouvements anormaux par la coagulation pallidale. Technique et résultats. Rev Neurol 1953;89:578-80.

16 Cooper IS, Bravo G. Chemopallidectomy and chemothalamectomy. $\mathcal{7}$ Neurosurg 1958;15:244-50.

17 Svennilson E, Torvik A, Lowe R, et al. Treatment of parkinsonism by stereotactic thermolesions in the pallidal region. A clinical evaluation of 81 cases. Acta Psychiatr Neurol Scand 1960;35:358-77.

18 Hughes AD, Daniel SE, Kilford L, et al. The accuracy of clinical diagnosis of idiopathic Parkinson's disease. F Neurol Neurosurg Psychiatry 1992;55:181-5.

19 Fahn S, Elton RLL, and members of the UPDRS Committee. Unified Parkinson's disease rating scale. In: S Fahn, CD Marsden, M Goldstein, et al, eds. Recent developments in Parkinson's disease. Vol 2. New York: MacMillan

20 Durif F, Vidailhet M, Debilly B, et al. Worsening of dyskinesias in Parkinson's disease by motor tasks and mental calculation. Mov Disord 1997;14:242-5.

21 Langston LW, Widner H, Goetz CG, et al. Core assessment program for intracerebral transplantations (CAPIT). Mov Disord 1992;7:2-13

22 Talairach J, David M, Tournoux P, et al. Atlas d'anatomie stéréotaxique. Repérage radiologique indirect des noyaux gris centraux des régions mésencéphalo-sous-optique et hypothalamique de l'homme. Paris: Masson, 1957.

23 Bejjani B, Damier P, Arnulf I, et al. Pallidal stimulation for Parkinson's disease: two targets ? Neurology 1997;49:1-7.

24 Shaltenbrand G, Bailey P. Introduction to stereotaxis with an atlas of the human brain. Vol II. New York: Grune and Stratton, 1959 .

25 Parent A. Basal ganglia. In: Parent A, ed. Carpenter's human neuroanatomy. 9th ed. Baltimore: Williams and Wilkins, 1996:795-854

26 Benazzouz A, Piallat B, Pollak P, et al. Responses of substantia nigra pars reticulata and globus pallidus complex to high frequency stimulation of the subthalamic nucleus in rats: electrophysiological data. Neurosci Lett 1995;189:7780 .

27 Albin RL, Young AB, Penney JB. The functional anatomy of basal ganglia disorders. TINS 1989;12:366-75.

28 Alexander GE, Crutcher MD. Functional architecture of basal ganglia circuits: neural substrates of parallel processing. TINS 1990;13:266-71.

29 Parent A, Hazrati LN. Functional anatomy of the basal ganglia. I The cortico-basal ganglia-thalamo-cortical loop. glia. I The cortico-basal gang
Brain Res Rev 1995;20:91-127.

30 Ceballos-Baumann AO, Obeso JA, Vitek JL, et al. Restoration of thalamocortical activity after posteroventral pallidotomy in Parkinson's disease. Lancet 1994;344:814.

31 Limousin P, Greene J, Pollak P, et al. Changes in cerebral activity pattern due to subthalamic nucleus or internal palidum stimulation in Parkinson's disease. Ann Neurol 1997; 42:283-91.

32 Filion M, Tremblay L, Bedard PJ. Effects of dopamine agonist on the spontaneous activity of globus pallidus neurons in monkeys with MPTP-induced parkinsonism. Brain Res 1991;547:152-61.

33 Hutchison WD, Levy R, Dostrovsky JO, et al. Effects of apomorphine on globus pallidus neurons in parkinsonian patients. Ann Neurol 1997;42:767-75.

34 Suarez JI, Metman LV, Reich SG, et al. Pallidotomy for hemiballismus: efficacy and characteristics of neuronal activity. Ann Neurol 1997;42:807-11.

35 Matsumara M, Tremblay L, Richard H, et al. Activity of pallidal neurons in the monkey during dyskinesia induced by injection of bicuculline in the external pallidum. Neurosciences 1995;65:59-70.

36 Tröster AI, Fields JA, Wilkinson SB, et al. Unilateral pallidal stimulation for Parkinson's disease: neurobehavioral functioning before and 3 months after electrode implantation. Neurology 1997;49:1078-83.

37 Volkmann J, Sturm U, Weiss P, et al. Bilateral highfrequency stimulation of the internal globus pallidus in
advanced Parkinson's disease. Ann Neurol 1998;44:953-61.

38 Krack P, Pollak P, Limousin P, et al. Subthalamic nucleus or internal pallidal stimulation in young onset Parkinson's disease. Brain 1998;121:451-7.

39 Hariz MI, De salles AA. The side-effects and complications of posteroventral pallidotomy. Acta Neurochir Suppl (Wein)
1997;68:42-8. 
40 Limousin P, Pollak P, Benazzouz A, et al. Effect on parkinsonian signs and symptoms of bilateral subthalamic nucleus stimulation. Lancet 1995;345:91-5.

41 Limousin P, Pollak P, Benazzouz A, et al. Bilateral subthalamic nucleus stimulation for severe Parkinson's disease. Mov Disord 1995;10:672-74.
42 Krack P, Pollak P, Limousin P, et al. Stimulation of subthalamic nucleus alleviates tremor in Parkinson's disease. Lanlamic nucleus alleviat

43 Krack P, Limousin P, Benabid AL, et al. Chronic stimulation of subthalamic nucleus improves levodopa-induced dyskinesias in Parkinson's disease. Lancet 1997;350:1676.

\section{HISTORICAL NOTE}

\author{
Some contributions of Duchenne de \\ Boulogne (1806-75)
}

PROGRESSIVE MUSCULAR ATROPHY

In 1849 Duchenne described a patient with spreading progressive muscular atrophy that started in the hands and spread slowly to the arms and legs, with no sensory signs, pain, or sphincter disturbance. Characteristically self effacing, he did not publish the case himself, but passed on his observations to François Amilcar Aran, physician to the Hôpital Saint Antoine. Aran published the paper ${ }^{1}$ and acknowledged: "I owe a thousand thanks to my friend Duchenne de Boulogne who freely put at my disposal all his material ..."

Duchenne's account (translated by G V Poore) followed in $1870^{2}$ : "Muscles . . . often jerked by little fibrillary or partial contractions . . . agitated with worm-like movements. Progressive muscular atrophy attacks the upper limbs, and destroys its muscles in an irregular fashion. It begins in such cases by attacking one after another the muscles of the thenar eminence, spreading from the superficial to the deep layer. As soon as the abductor pollicis is wasted, its absence is marked by a depression, and by the attitude, during repose, of the first metacarpal bone, which lies too close to the second... Depressions of the hypothenar eminence and interosseal spaces next announce the atrophy of the muscles of those regions. The loss of the interossei muscles is shown by the claw-like attitude of the fingers ... The atrophy may remain localised for many years ... The flexors of the elbow and the deltoid are the first to atrophy. The triceps extensor cubiti is the last of the muscles of the upper limb to become affected. . . . Whenever all muscles of the arm have been atrophied, I have found a greater or lesser number of muscles of the trunk in the same condition . . . first, the lower half of the trapezius ... I have usually seen the muscles of breathing and swallowing become affected. The atrophy equally invades the lower limbs, but only when the muscles of the upper limbs and trunk are in great part destroyed. It is most marked in the flexors of the ankle and hip. I have not seen atrophy attack both sides at once, but when one muscle is affected the corresponding muscles are usually attacked at no distant time."

He also wrote: “. . . (I have) only seen it begin in the lower limbs . . twice out of 159 cases ... in a good third of cases that electromuscular sensibility, as well as cutaneous sensibility was more or less weakened . ... (There are) "change of form and attitude," superficial deformities, "functional troubles during voluntary action," and he notes the "wasting of intercostals and diaphragm ... a great hindrance to breathing, and still more to phonation ... there is no paralysis of the bladder or rectum ... Duration.-This is very variable.
The diseasemay reach its last stage in less than two years ... I have seen it in this way remain localised for some eight or nine years.. Electromuscular contractility is normal. beyond doubt."

Pathologically, Duchenne reported the loss of striation, replacement by granular matter and fat vesicles, and fascicular atrophy of the muscles. But, he prefaces his account by saying that: "the feebleness of contractility . . . is chiefly the consequence of the wasting, ... and not the result of paralysis, i.e. of a failure of the motor nerve action."

MUSCLE DISEASE AND “DUCHENNE'S DYSTROPHY” His investigations of muscle disease continued with his invention of the "harpoon" that he employed to perform percutaneous muscle biopsies; not surprisingly, this aroused hostile criticism of its ethical propriety in the local press. The discovery of pseudo-hypertrophic paralysis, or myo-sclerotic paralysis in $1868,{ }^{3}$ was however, a remarkable and important contribution, dependent on and illustrated by pictures of histology obtained by harpoon biopsy: "This disease is mainly characterised: 1 . By feebleness of movement, usually situated at first in the muscles of the lower extremities and of the lumbar spine, ultimately spreading progressively to the upper limbs, and increasing in intensity till all movement is lost; 2 . increase in size of most of the paretic muscles; 3. By increase of the interstitial connective tissue of the paretic muscles, and in the more advanced stages by an abundant production of fibrous tissue or of fatty globules. The name I have given to this disease pseudohypertrophic muscular paralysis ... has reference to the symptoms.... It may be called myo-sclerotic paralysis, a name which is more scientific and justified by pathological anatomy."

Of his many other contributions were original descriptions of the use of photography of microscopic histology, tabetic locomotor ataxia which contemporaries had confused with Friedreich's disease, the anterior horn cell lesions, which caused acute poliomyelitis, and glossolabio-laryngeal paralysis (bulbar palsy).

Guillaume Benjamin Amand Duchenne was the son of a long lineage of seafarers and fishermen in the region of Boulogne sur Mer. According to Laségue and Strauss, he was of the middle height, thickset, active in movement, slow of speech and retaining to the last a faint provincial accent. He studied medicine in the University of Paris, under Laennec, Cruveilhier, and Dupuytren. $\mathrm{He}$ graduated in 1831. He returned to Boulogne to a limited private practice, but was badly affected by his young wife's death in childbirth. He lived only for his patients and for his scholarship.

Lonely and isolated from his friends, he returned to Paris in 1842 and started to experiment with Faradic current on the function of skeletal muscle. He sought no forma appointment, but attended patients in many Parisian hospitals, questioning and examining patients with laborious obsession, often following their progress by visiting them in their homes for many years. At times, he was humiliated by established physicians: "the monarchs of the wards", he called them. His reputation slowly increased, despite a neglect of pathological anatomy, and his dependence on his own observations rather than on neurological writings. Later in life he concentrated more on the nervous system than on muscles, taking up histology with youthful zest. Both Charcot and Trousseau fostered his recognition and showed him great respect: Charcot's lectures contain frequent acknowledgement of his work.

Neither succinct as a writer, nor systematic in his work, his lengthy papers emerged slowly. His first, L'Electrisation Localisée et de son application à la pathologie et à la thérapeutique, was published in 1855, was well received, and encouraged more research and trials of electrotherapy; by 1872 it had achieved a third edition. ${ }^{2}$ In 1862 his previously estranged son joined him in Paris. $\mathrm{He}$ started, at last, to gain international respect. This culminated in election to many medical societies throughout Europe. A final disaster occurred when his son died of typhoid fever in 1871, with grave and lasting effects on his personal life. He died of a cerebral haemorrhage in 1875

His epitaph we can leave to Charcot who remarked : "How is it that one fine morning Duchenne discovered a disease that probably existed in the time of Hippocrates? Why do we realise things so late, so poorly, with such difficulty.....Because our minds have to take in something that upsets our original set of ideas . .." A bas-relief in the Salpêtrière shows the doctor attending his patient, applying electrodes attached to a simple generator. The accompanying plaque reads:

\begin{tabular}{|c|}
\hline A. Duchenne (de Boulogne) \\
Electrisation Localisée \\
Physiologie des Mouvements \\
Neuropathologie
\end{tabular}

Postscript: Edward Meryon (1807-) presented a paper to the Royal Medico-chirugical society on 9 December, 1851, which described two typical "Duchenne" families and one with Becker type dystrophy. $\mathrm{He}$ recognised them as primary diseases of muscle ${ }^{5}$ and showed postmortem the typical "granular degeneration"6

J M S PEARCE 304 Beverley Road, Anlaby, Hull HU10 7BG, UK

1 Aran FA. Archives Génerales de Médicine 1850; 4(sér 24):4-35.

2 Duchenne GBA. In: L'Electricisation Localisée, 3rd ed. 1872:486-563. Translated by GV Poore. In: Selections from the clinical works of Dr Duchenne (de Boulogne). London: The New Sydenham Society, 1883:42-87.

3 Duchenne GBA. Archives Génerales de Médicine 1868;6(ser 11):5-25; 179-209;305-2; 421-43; 552-88.

4 Haymaker W, Schiller F, eds. The founders of neurology, 2nd ed. Springfield. Charles C Thomas, 1970:430-4.

5 Meryon E. Lancet 1852:2:588-9.

6 Meryon E. Medico-chirugical transactions 1852; 35:73-84 